\title{
EFFECT OF ALUMINUM CONTENT AND PRECIPITATION ON THE CORROSION BEHAVIOR AND ACOUSTIC EMISSION RESPONSE OF AZ31 AND AZ80 MAGNESIUM ALLOYS
}

\author{
${ }^{1}$ Eliška VEVERKOVÁ, ${ }^{1,2}$ Michal KNAPEK, ${ }^{1}$ Peter MINÁRIK \\ ${ }^{1}$ Charles University, Department of Physics of Materials, Prague, Czech Republic, EU, \\ ve.eliska@gmail.com,knapek@karlov.mff.cuni.cz, peter.minarik@mff.cuni.cz \\ ${ }^{2}$ The Czech Academy of Sciences, Nuclear Physics Institute, Řež, Czech Republic, EU
}

https://doi.org/10.37904/metal.2019.940

\begin{abstract}
In this study, we investigated the effect of aluminum content and precipitation on the corrosion behavior of the AZ31 and AZ80 magnesium alloys. The investigated alloys were received in the as-extruded condition in order to retain comparable grain size and texture. First, solid solution treatment was performed on the samples of both alloys. Subsequently, the samples were isothermally aged at $200^{\circ} \mathrm{C}$ for 20 hours. The scanning electron microscopy was used to study the grain size and microstructure. The corrosion properties of samples were studied by potentiodynamic polarization measurements and the AE signal was concurrently recorded. Solution treated $A Z 80$ and $A Z 31$ samples exhibited similar behavior. The aged AZ80 sample showed lower corrosion rate. Also, a strong breakdown appeared in the later (compared to other samples) stage of the potentiodynamic test. The breakdown was found to be easily recognized by $A E$ parameters.
\end{abstract}

Keywords: Magnesium alloys, corrosion, acoustic emission, polarization

\section{INTRODUCTION}

Magnesium alloys are well known for their unique mechanical properties such as low density and high specific strength. For example, they are commonly used in the automotive industry in order to reduce weight of components [1]. On the other hand, their application is significantly limited due to low corrosion resistance $[2,3]$. The most commercially used magnesium alloys are of type AZ (Mg-Al-Zn), typically AZ31, AZ61, AZ80 and AZ91. These alloys exhibit good strength, good castability and relatively good corrosion resistance [3-5]. Nevertheless, magnesium is usually very susceptible to galvanic corrosion, which often occurs in these alloys [6]. More noble $\beta$-phase, $\mathrm{Al}_{12} \mathrm{Mg}_{17}$, typically acts as a cathode and increases corrosion rate. On the other hand, it was found that $\beta$-phase may also act as a barrier against corrosion propagation $[7,8]$. Therefore, the microgalvanic corrosion and, consequently, the corrosion resistance of the alloy strongly depends on the size and distribution of the $\beta$-phase $[9,10]$.

Corrosion behavior is usually studied by the standard electrochemical tests, e.g. potentiodynamic polarization (PD) test. However, PD test does not provide comprehensive information about the underlying corrosion process. It was shown that analysis of the acoustic emission (AE) signal, which can be recorded in-situ during the PD test, can provide additional information regarding corrosion process. This method was found to be very sensitive to the rupture of the protective film and pitting corrosion (see Ref. [11] and references therein).

In this paper, the AE analysis was used to study corrosion behavior during the PD test on two AZ-type magnesium alloys with different content of aluminum and different distribution of precipitates.

\section{MATERIAL AND EXPERIMENTAL METHODS}

Two commercial magnesium alloys AZ31 and AZ80 were supplied in the form of extruded rods. Their chemical composition is listed in Table 1. The as-extruded condition was selected in order to suppress possible effect of different grain size and texture on the corrosion behavior. Microstructure investigation revealed that $\beta$ - 
$\mathrm{Al}_{11} \mathrm{Mg}_{17}$ secondary phase particles were present in both as-received materials. Therefore, the first step was the solid solution treatment. Annealing was performed for 1 hour at $430{ }^{\circ} \mathrm{C}$ with subsequent quenching into water, according to Ref. [12]. Afterwards, samples from both alloys were aged at $200{ }^{\circ} \mathrm{C}$ for 20 hours. Hereafter, the samples are denoted as AZ31-ST and AZ80-ST, representing the solid solution treated samples and AZ31-An and AZ80-An, representing the artificially aged (annealed) samples.

Table 1 Chemical composition of magnesium alloys

\begin{tabular}{|c|c|c|c|}
\hline \multirow{2}{*}{ Alloy } & \multicolumn{3}{|c|}{ Content of alloying elements in wt. \% } \\
\cline { 2 - 4 } & Al & Zn & Mn \\
\hline AZ31 & 3.0 & 1.0 & 0.3 \\
\hline AZ80 & 8.5 & 0.5 & 0.12 \\
\hline
\end{tabular}

Microstructure of the aged samples, particularly distribution of the $\beta$-phase, was investigated by the scanning electron microscope (SEM) ZEISS Auriga Compact. Samples for SEM were mechanically polished down to $1 \mu \mathrm{m}$ and subsequently electropolished using Struers Lectropol and Struers AC2 solution.

Corrosion tests were performed using a standard three-electrode setup. In addition, the AE response was concurrently recorded. A specially designed corrosion cell was used, see the schematic diagram in Figure 1 and detailed description in [11]. Surface area of samples exposed to corrosion agent was $0.5 \mathrm{~cm}^{2}$. Potentiodynamic polarization tests were performed from -0.15 to $0.2 \mathrm{~V}$ (with respect to the open circuit potential, step $0.001 \mathrm{~V} \cdot \mathrm{s}^{-1}$ ) after 1 hour of stabilization at the room temperature. The $3.5 \% \mathrm{NaCl}$ solution (of $\mathrm{pH} 7$ ) prepared using deionized water was used as the corrosion medium. Before each test, the sample was ground using FEPA P1200 sandpaper, rinsed with ethanol and dried with compressed $\mathrm{CO}_{2}$. At least three tests were performed for each sample.

The AE signal was collected using a computer-controlled acquisition board Physical Acoustics Corporation (PAC) PCl-2. Piezoelectric AE sensor (PAC Micro30S) was attached to the sample with a screw. Good acoustic contact between the sensor and the sample was facilitated using the Apiezon vacuum grease. The signal was preamplified (PAC 2/4/6 preamplifier, gain of $60 \mathrm{~dB}$ ) and recorded at a sampling rate of $2 \mathrm{MHz}$. The threshold was set to $23 \mathrm{~dB}$, i.e., slightly above the noise level. The AE events and their parameters, such as amplitude and cumulative counts, were extracted using standard threshold-based event individualization.

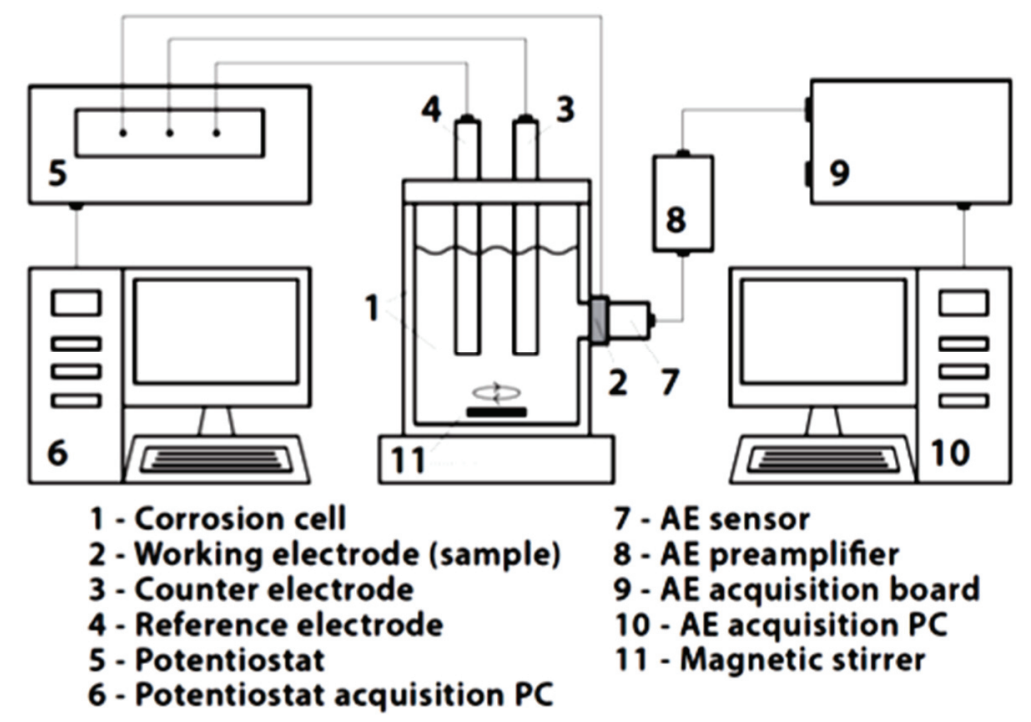

Figure 1 Experimental set-up for the PD tests with concurrent AE recording [11] 


\section{RESULTS AND DISCUSSION}

\subsection{Microstructure}

The solid solution treatment at $450{ }^{\circ} \mathrm{C}$ was found to be effective in dissolving the $\beta$-phase. The SEM observation did not reveal any residual particles, regardless of a relatively short annealing time. It was shown that much longer annealing should be typically used for a cast material, where large particles are present $[10,13]$. Subsequent aging at $200{ }^{\circ} \mathrm{C}$ resulted in homogenous formation of fine $\mathrm{Al}_{12} \mathrm{Mg}_{17}$ precipitates in the AZ31 alloy, whereas simultaneous occurrence of continuous and discontinuous precipitation was observed in the AZ80-An sample [13]. Consequently, a significant difference in the secondary phase distribution occurred after the aging, as depicted in Figure 2.
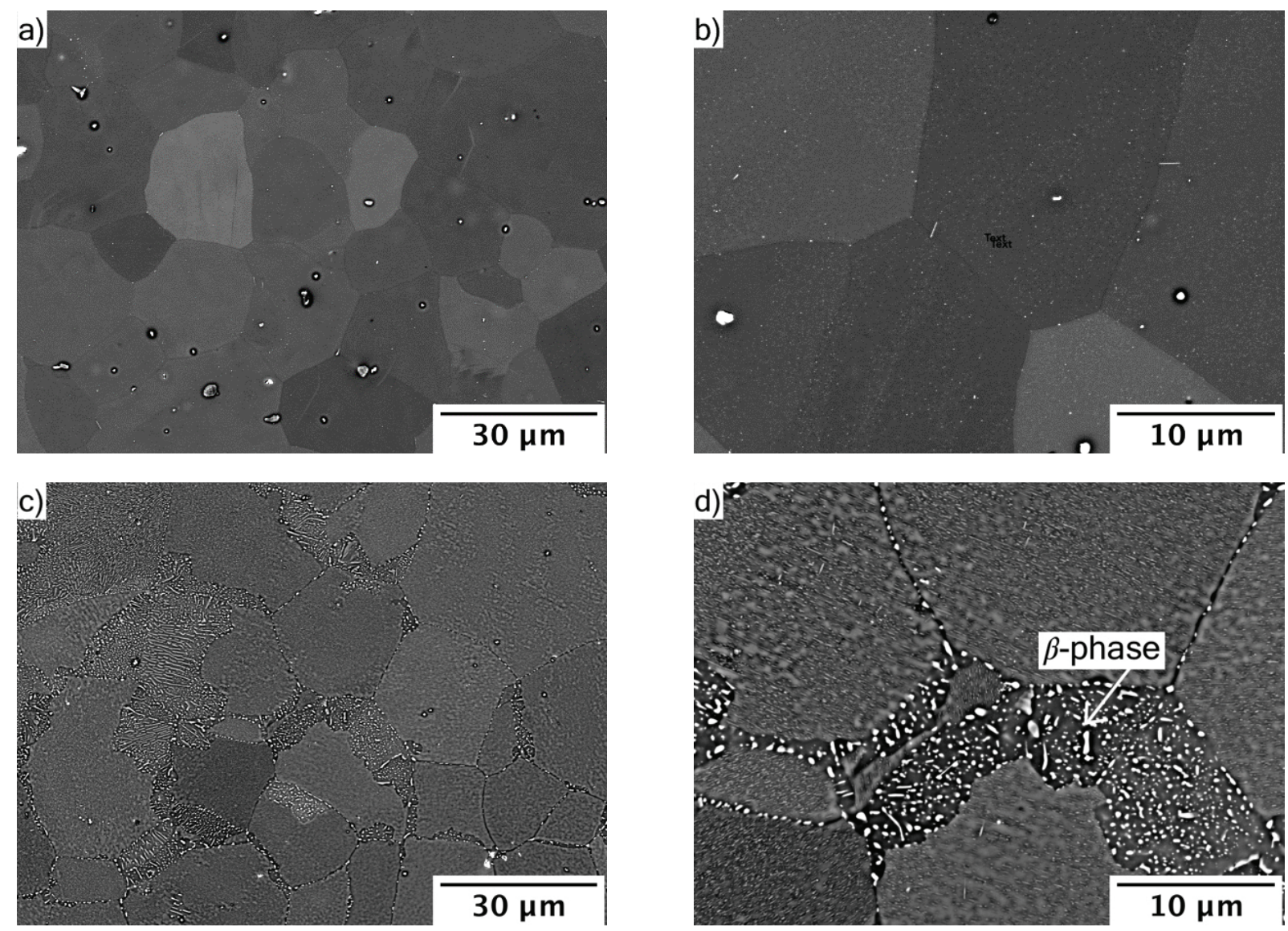

Figure 2 SEM micrographs (BSE signal) of the investigated samples after solution treatment and aging

a), b) AZ31 and c), d) AZ80

\subsection{Corrosion tests}

The polarization curves of all four samples are presented in Figure 3. Corresponding values of the corrosion potential $E_{c o r}$ and corrosion current density $i_{c o r}$ were evaluated by Tafel analysis and the results are listed in Table 2. The data show that there is a negligible difference in the corrosion current density and corrosion potential between the two investigated alloys in the ST condition. Moreover, aging of the AZ31 alloy did not significantly affect these values. On the other hand, in case of the AZ80 alloy, aging lead to a significant decrease of corrosion current density and a slight shift of corrosion potential to more noble values. The improvement of the corrosion resistance could be associated with the formation of protective layer and passivation during stabilization. The break-down potential was observed at $-1.4 \mathrm{~V}$ vs. SCE. 


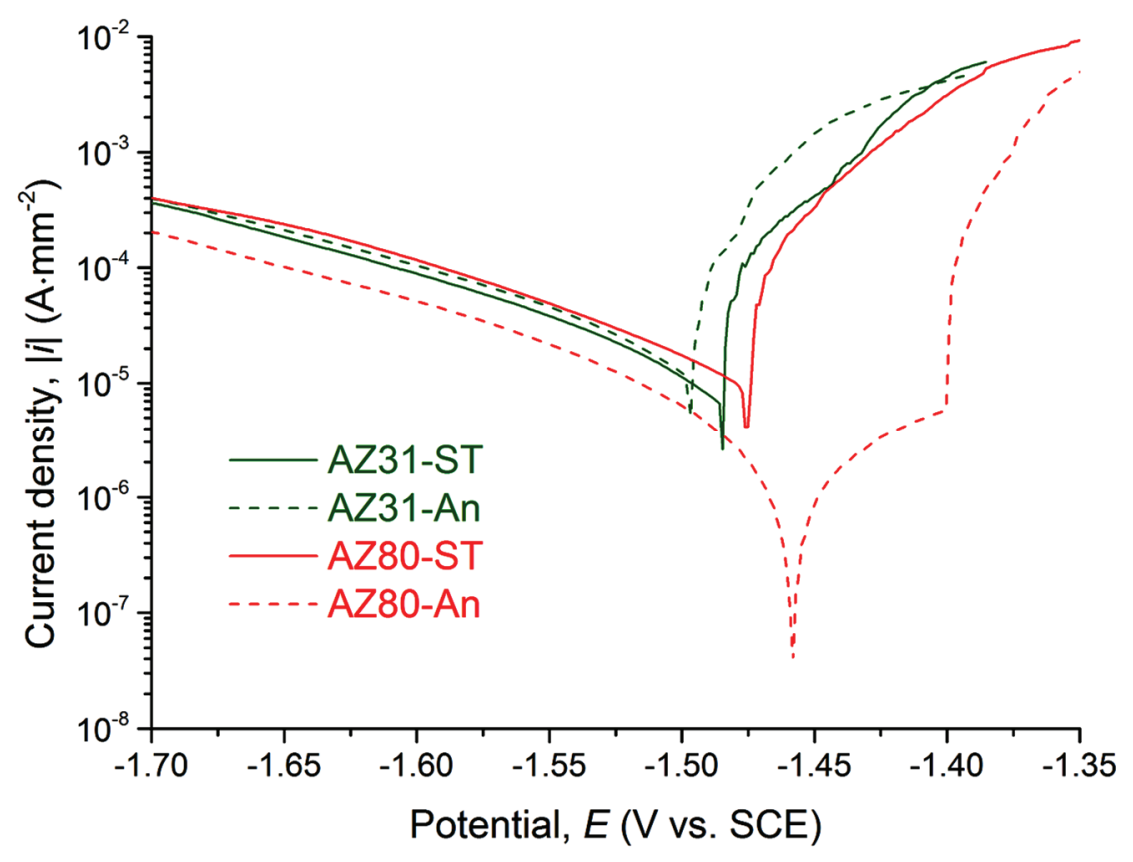

Figure 3 Polarization curves of the investigated samples

Table 2 Corrosion potentials and current densities

\begin{tabular}{|c|c|c|c|c|}
\hline Sample & AZ31-ST & AZ31-An & AZ80-ST & AZ80-An \\
\hline$E_{\text {cor }}(\mathrm{V})$ & -1.49 & -1.50 & -1.48 & -1.46 \\
\hline $\boldsymbol{i}_{\text {cor }}\left(\mathrm{A} \cdot \mathrm{cm}^{-2}\right)$ & $1.7 \cdot 10^{-5}$ & $3.2 \cdot 10^{-5}$ & $2.4 \cdot 10^{-5}$ & $7.8 \cdot 10^{-7}$ \\
\hline
\end{tabular}

The $A E$ event parameters evaluated from the raw $A E$ signal recorded during corrosion tests are shown in Figure 4. Analogous to the polarization curves, evolution of the $A E$ parameters as a function of time (polarization) was comparable for both alloys in the ST condition and the AZ31-An sample. Prior to reaching the corrosion potential, the AE signals were discrete and intermittent, as reflected by a marginal increase of cumulative counts while the signal amplitudes were rather high. This behavior is related to the cathodic overpotential, which is relatively high in the beginning of the test and decreases towards $E_{c o r}$. Therefore, due to the decreasing tendency of $\mathrm{H}_{2}$ formation, less bubbles are being formed, but variation in their size increases. Consequently, as depicted in Figure 4, variation in amplitudes increases towards $E_{c o r}$. Significant increase of the corrosion current density right from the beginning of the anodic part of the PD scan, together with a significant increase of both AE parameters, indicate that all three samples (AZ31-ST, AZ80-ST, AZ31- An) are not protected by a protective layer despite 1 hour of stabilization. As was shown in the previous study, a rapid increase in the AE amplitudes and counts can be associated with active corrosion process [11]. Pitting corrosion, which is often observed in this class of magnesium alloys, initiates and increases its intensity with rising anodic overpotential. Consequently, both $A E$ parameters, namely amplitude and cumulative counts increase accordingly [11]. On the other hand, the AZ80-An sample exhibited different corrosion development. The breakdown potential was shifted to a more positive value $(-1.40 \mathrm{~V}$ vs. SCE). This breakdown clearly recognized also from the $P D$ polarization curve was accompanied by a sharp increase of continuous $A E$ activity. It is worth noting that in this sample the AE activity practically diminished before the breakdown potential. All these observations, therefore, bear evidence that passivation of the AZ80-An sample was much more pronounced compared with the other three samples. These results are in agreement with other studies, where formation of finely distributed $\beta$-phase precipices was found to have a positive effect on the stability of the protective layer, especially within the first hours of immersion $[10,14]$. 
a)

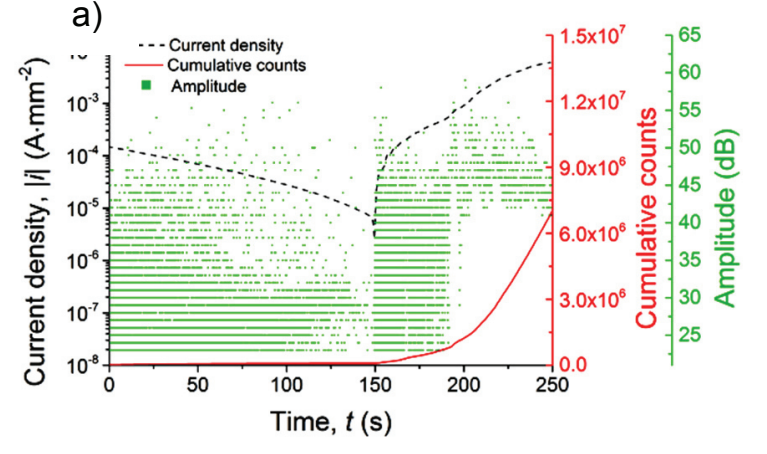

c)

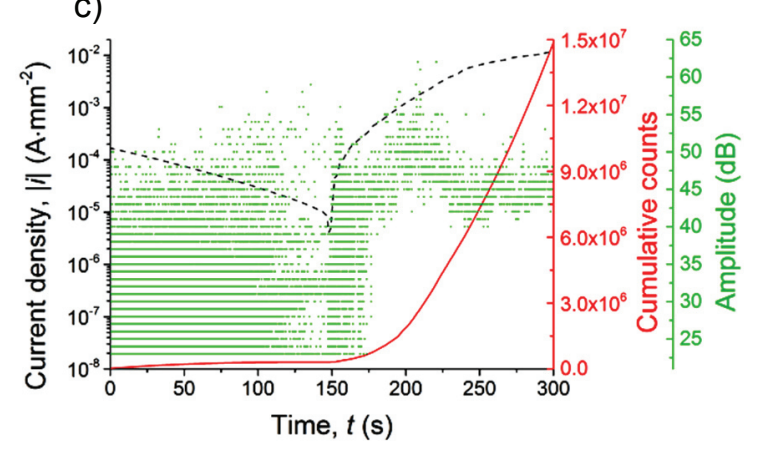

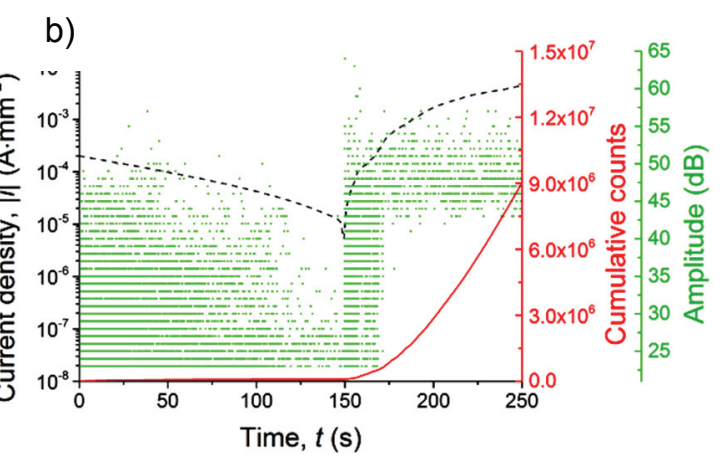

d)

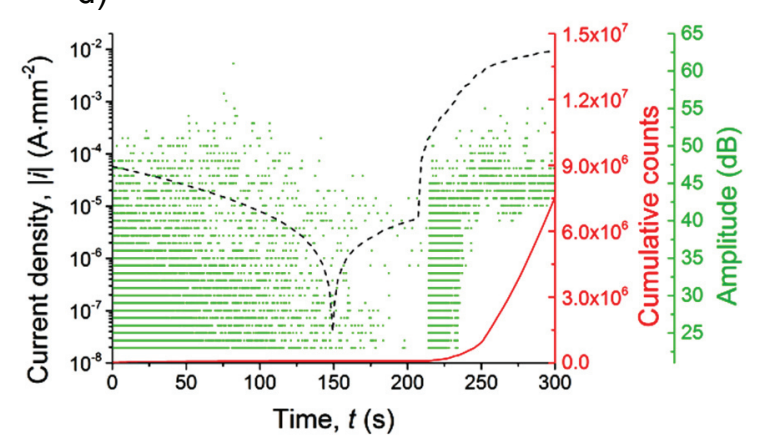

Figure 4 Acoustic emission data collected during the PD polarization test on

a) AZ31-ST, b) AZ31-An, c) AZ80-ST, and d) AZ80-An samples

\section{CONCLUSION}

The PD polarization tests and concurrent AE recording were used to monitor the corrosion behavior of AZ31 and AZ80 magnesium alloy samples in two conditions: (i) solution treated samples and (ii) solution treated and artificially aged $\left(200{ }^{\circ} \mathrm{C}, 1\right.$ hour) samples. The solution treated AZ31, aged AZ31, and solution treated AZ80 samples showed similar response in terms of the electrochemical tests and also the AE parameters. On the other hand, the aged AZ80 sample exhibited different behavior. The distinction could be clearly seen in the corrosion rate (lowered by annealing) and the shape of the corrosion curve, as a strong breakdown could be recognized only it the later stage of the PD test, reflecting significant surface passivation during the test. On the other hand, the breakdown in the other samples took place already around the corrosion potential. The breakdown is related to the activation of stable pitting corrosion and was also recognized by AE by means of the occurrence of strong continuous signals in all the samples.

\section{ACKNOWLEDGEMENTS}

This work was financially supported by the Czech Science Foundation under the project 19-08937S. M.K. gratefully acknowledges financial support from the Operational Programme Research, Development and Education, The Ministry of Education, Youth and Sports (OP RDE, MEYS), grant No. CZ.02.1.01/0.0/0.0/16_013/0001794.

\section{REFERENCES}

[1] MORDIKE, B.L. and EBERT, T. Magnesium: Properties - applications - potential. Materials Science and Engineering: A. 2001. vol. 302, no. 1, pp. 37-45. 10.1016/S0921-5093(00)01351-4 
[2] PARDO, A., MERINO, M.C., COY, A.E., ARRABAL, R., VIEJO, F. and MATYKINA, E. Corrosion behaviour of magnesium/aluminium alloys in 3.5 wt.\% NaCl. Corrosion Science. 2008. vol. 50, no. 3, pp. 823-834. 10.1016/j.corsci.2007.11.005

[3] CHENG, Y., QIN, T., WANG, H. and ZHANG Z. Comparison of corrosion behaviors of AZ31, AZ91, AM60 and ZK60 magnesium alloys. Transactions of Nonferrous Metals Society of China. 2009. vol. 19, no. 3, pp. 517-524. 10.1016/S1003-6326(08)60305-2

[4] KABIRIAN, F. and MAHMUDI, R. Impression creep behavior of a cast AZ91 magnesium alloy. Metallurgical and Materials Transactions A. 2008. vol. 40, no. 1, p. 116. 10.1007/s11661-008-9699-7

[5] LI, J., XIE, J. JIN, J. and WANG, Z. Microstructural evolution of AZ91 magnesium alloy during extrusion and heat treatment. Transactions of Nonferrous Metals Society of China. 2012. vol. 22, no. 5, pp. 1028-1034. 10.1016/S1003-6326(11)61279-X

[6] SKAR, J.I. Corrosion and corrosion prevention of magnesium alloys. Materials and Corrosion. 1999, vol. 50, no. 1, pp. 2-6. 10.1002/(SICI)1521-4176(199901)50:1<2::AID-MACO2>3.0.CO;2-N

[7] SONG, G. Recent Progress in Corrosion and Protection of Magnesium Alloys. Advanced Engineering Materials. 2005, vol. 7, no. 7, pp. 563-586. 10.1002/adem.200500013

[8] WINZER, N., ATRENS, A., SONG, G., GHALI, E., DIETZEL, W., KAINER, K.U., HORT, N. and BLAWERT, C. A Critical review of the stress corrosion cracking (SCC) of magnesium alloys. Advanced Engineering Materials. 2005. vol. 7, no. 8, pp. 659-693. 10.1002/adem.200500071

[9] PARDO, A., MERINO, M.C., COY, A.E., VIEJO, F., ARRABAL, R. and FELIÚ, S. Influence of microstructure and composition on the corrosion behaviour of Mg/Al alloys in chloride media. Electrochimica Acta. 2008. vol. 53, no. 27, pp. 7890-7902. 10.1016/j.electacta.2008.06.001

[10] ZHAO, M.-C., LIU, M., SONG, G. and ATRENS, A. Influence of the $\beta$-phase morphology on the corrosion of the Mg alloy AZ91. Corrosion Science. 2008. vol. 50, no. 7, pp. 1939-1953. 10.1016/j.corsci.2008.04.010

[11] KNAPEK, M., MINÁRIK, P., ČAPEK, J., KRÁL, R., KUBÁSEK, J. and CHMELÍK, F. Corrosion of pure magnesium and a WE43 magnesium alloy studied by advanced acoustic emission analysis. Corrosion Science. 2018. vol. 145, pp. 10-15. 10.1016/j.corsci.2018.09.006

[12] BOHLEN, J., TELLERIA IPARRAGIRRE, A., ARRUEBARRENA, G. and LETZIG, D. On the Age Hardening Response of Aluminum Containing Magnesium Sheets with Zinc or Manganese (AZ- and AM Series Alloys). In: Kiran N. SOLANKI, Dmytro ORLOV, Alok SINGH and Neale R. NEELAMEGGHAM, eds. Magnesium Technology 2017. B.m.: Springer International Publishing, 2017. The Minerals, Metals \& Materials Series, p. 113-121. ISBN 978-3-319-52392-7.

[13] BRASZCZYŃSKA-MALIK, K.N. Discontinuous and continuous precipitation in magnesium-aluminium type alloys. Journal of Alloys and Compounds. 2009. vol. 477, no. 1, pp. 870-876. 10.1016/j.jallcom.2008.11.008

[14] AUNG, N.N. and ZHOU, W. Effect of grain size and twins on corrosion behaviour of AZ31B magnesium alloy. Corrosion Science. 2010. vol. 52, no. 2, pp. 589-594. 10.1016/j.corsci.2009.10.018 